\title{
Improving Colorectal Cancer Screening at an Employer-Sponsored Health Plan During the COVID-19 Pandemic
}

KEY WORDS: FIT; colorectal cancer; COVID-19.

J Gen Intern Med 37(5):1334-6

DOI: $10.1007 / \mathrm{s} 11606-022-07426-3$

(C) The Author(s) under exclusive licence to Society of General Internal Medicine 2022

\section{INTRODUCTION}

As the COVID-19 pandemic increased in intensity, many United States medical centers halted non-urgent and elective medical procedures ${ }^{1}$, including colorectal cancer (CRC) screenings ${ }^{2}$ which already have poor screening rates prior to the pandemic. ${ }^{3}$ Recent US studies have shown the effectiveness of using mailed fecal immunochemical tests (FITs) programs to increase CRC screening rates. ${ }^{4}{ }^{5}$ Given the limited resources during the pandemic and low CRC screening, our academic medical center launched a CRC screening initiative, and we report on the results of this initiative and the characteristics of those who received screening through this program.

\section{METHODS}

The clinical leadership team convened a multidisciplinary workgroup to improve CRC screening rates and identified screening with FIT kits as a potential solution. Polymedco OC-Auto FIT kits were mailed to members at home, and provided instructions with pre-addressed, and postage-paid return envelopes, as well as an informational letter outlining the value of screening. A standardized order for laboratory processing of mailed specimens was developed alongside a protocol to direct results to the patient's primary care provider. Samples were delivered to a satellite lab, processed, and inputted directly into the electronic medical record (EMR), triggering a notification to the patient's primary care provider for follow-up. Members with questions were directed to designated staff who addressed concerns and

Prior Presentations None

Received September 30, 2021

Accepted January 19, 2022

Published online February 7, 2022 any laboratory issues to improve return results. Inclusion criteria for the initiative were membership in the institution's health plan for its employees and their families, and aged 50-75 years without an up-to-date CRC screening. The Institutional Review Board at the University of Southern California approved this study (UP 2100239). Patient information was acquired from the MR and anonymized. All analyses were performed using SAS, version 9.4 (SAS Institute Inc., Cary, NC, USA).

\section{RESULTS}

FIT tests were mailed to 578 members between July 2020 and January 2021. Demographic data were available for 556 members $(96.2 \%)$. The mean age was 60.3 years and $52.9 \%$ were female. The population was racially and ethnically diverse: $48.7 \%$ White, $15.5 \%$ Asian, $10.3 \%$ Black or African American, and 7.7\% Hispanic or Latino. Twenty-eight percent of all mailed members and $29.3 \%$ of members with demographic data returned a completed FIT (Table 1). Six positive FIT tests were received, and all were referred for colonoscopy of which six (100\%) received a colonoscopy, with one revealing colon cancer. Those who returned the FIT were older than those who did not $(P=0.03)$. There were no other differences between the two groups' characteristics, and multi-variate analysis did not identify any statistically significant risk factors between the groups. The CRC screening rate for the employee population in 2020 was $49 \%$. This is a $10 \%$ absolute increase and $25.6 \%$ relative increase from the previous year's screening rate of $39 \%$ (Fig. 1).

\section{DISCUSSION}

During the COVID-19 pandemic, cancer screening rates have decreased which may be due to limited in-person primary care visits. Our health system historically relied on colonoscopy as the primary modality for CRC screening. Given members' hesitancy to come to the medical center during the pandemic, we successfully mailed FIT kits to promote colorectal cancer screening of institution- 
Table 1 Patient Demographics

\begin{tabular}{|c|c|c|c|c|}
\hline & All members & FIT completed & FIT incomplete & $P$-value \\
\hline & $n=556$ & $n=163$ & $n=393$ & \\
\hline & Mean (SD) & Mean (SD) & Mean (SD) & \\
\hline Age (years) & $\begin{array}{l}60.3(6.0) \\
n(\%)\end{array}$ & $\begin{array}{l}61.2(5.9) \\
n(\%)\end{array}$ & $\begin{array}{l}60.0(6.0) \\
n(\%)\end{array}$ & 0.03 \\
\hline $\begin{array}{l}\text { Sex } \\
\text { Male } \\
\text { Female } \\
\text { Missing }\end{array}$ & $\begin{array}{l}259(46.6) \\
294(52.9) \\
3(0.5)\end{array}$ & $\begin{array}{l}79(48.5) \\
81(49.7) \\
3(1.8)\end{array}$ & $\begin{array}{l}180(45.8) \\
213(54.2) \\
0\end{array}$ & 0.4 \\
\hline $\begin{array}{l}\text { Race } \\
\text { American Indian/Alaska Native } \\
\text { Asian } \\
\text { Black or African American } \\
\text { Hawaiian/Pacific Islander } \\
\text { White } \\
\text { Multiple } \\
\text { Other } \\
\text { Patient refuses/doesn't know } \\
\text { Missing }\end{array}$ & $\begin{array}{l}2(0.4) \\
86(15.5) \\
57(10.3) \\
2(0.4) \\
271(48.7) \\
2(0.4) \\
62(11.2) \\
69(11.4) \\
5(0.9)\end{array}$ & $\begin{array}{l}1(0.6) \\
25(15.3) \\
16(9.8) \\
0 \\
85(53.3) \\
1(0.6) \\
11(6.8) \\
21(12.9) \\
3(1.8)\end{array}$ & $\begin{array}{l}1(0.3) \\
61(15.5) \\
41(10.4) \\
2(0.5) \\
186(47.3) \\
1(0.3) \\
51(13) \\
48(12.2) \\
2(0.5)\end{array}$ & 0.5 \\
\hline $\begin{array}{l}\text { Ethnicity } \\
\text { Hispanic or Latino } \\
\text { Non-Hispanic or Latino } \\
\text { Patient refuses/doesn't know } \\
\text { Unknown } \\
\text { Missing }\end{array}$ & $\begin{array}{l}43(7.7) \\
492(88.5) \\
15(2.7) \\
1(0.2) \\
5(0.9)\end{array}$ & $\begin{array}{l}6(3.7) \\
148(90.8) \\
6(3.8) \\
0 \\
3(1.8)\end{array}$ & $\begin{array}{l}37(9.4) \\
344(88.0) \\
9(2.3) \\
1(0.3) \\
2(0.5)\end{array}$ & 0.1 \\
\hline $\begin{array}{l}\text { Language preference } \\
\text { English } \\
\text { Spanish } \\
\text { Missing }\end{array}$ & $\begin{array}{l}547(99.3) \\
4(0.7) \\
5(0.9)\end{array}$ & $\begin{array}{l}159(97.6) \\
1(0.6) \\
3(1.8)\end{array}$ & $\begin{array}{l}388(98.7) \\
3(0.8) \\
2(0.5)\end{array}$ & 1.0 \\
\hline $\begin{array}{l}\text { FIT completion } \\
\text { Yes } \\
\text { Negative result }\end{array}$ & $163(29.3)$ & $\overline{1} 57(96.3)$ & - & \\
\hline
\end{tabular}

FIT fecal immunochemical test, SD standard deviation

insured employees and their family members. The initiative's promising rate of return of FIT kits $(28.2 \%)$ - as compared to average return rates of $10-28 \%$ seen in prior studies ${ }^{6}$ and plummeting pandemic screening rates-may suggest that some patient populations are open to at-home screenings. There are some limitations to the study: the initiative only included employees and their families with the institution's health plan therefore reflects a small sample size and may differ from other patient populations. The increased screening rate may be due to the mailer campaign; however, the pandemic may also have attributed to members more willing to participate in an organized screening program. With the initial launch of the mailed CRC screening program, the institution is looking to sustain this strategy for its employee population and their families in a yearly basis.

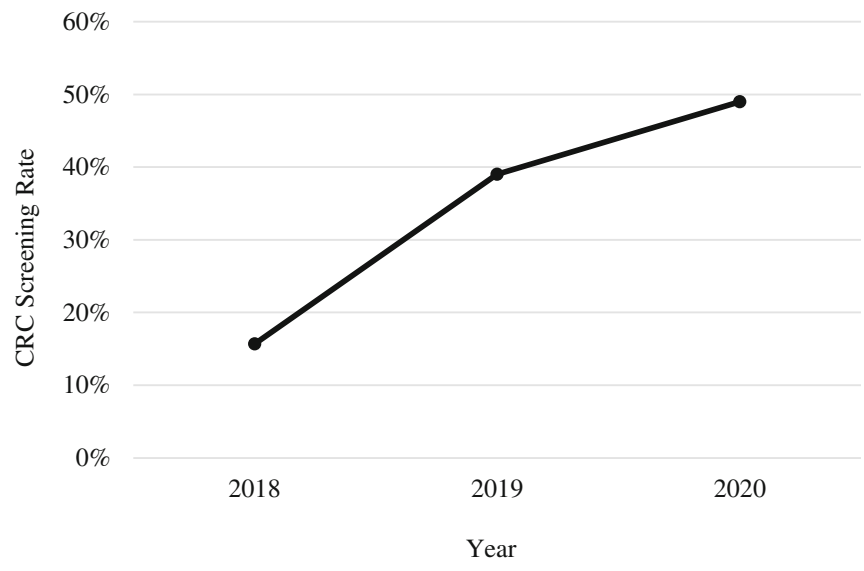

Fig. 1 Employee CRC screening rates from 2018 to 2020. 
Acknowledgements: The authors thank the members of the Elizabeth Garrett Colorectal Cancer Screening Workgroup for their commitment and diligence in pushing this project forward. We would also like to thank the Value Based Services Organization clinical team for their dedication to this quality improvement project.

Jeniffer S. Kim, PhD, MPH ${ }^{1}$

Omar Bakr, MD, MPH ${ }^{2}$

Mimi Xu, $M D^{2}$

Michael Hochman, MD, $M P H^{2}$

Veronica M. Pagán, MA, MPH ${ }^{1}$

${ }^{1}$ Gehr Family Center for Health Systems Science \& Innovation, Keck School of Medicine, University of Southern California,

Los Angeles, CA, USA

${ }^{2}$ Department of Medicine, Keck School of Medicine, University of Southern California,

Los Angeles, CA, USA

Corresponding Author: Mimi Xu, MD; Department of Medicine, Keck School of Medicine, University of Southern California, Los Angeles, CA, USA (e-mail: mimi.xu@med.usc.edu).

\section{Declarations:}

Conflict of interest: The authors declare that they do not have a conflict of interest.

\section{REFERENCES}

1. Centers for Medicare \& Medicaid Services. Non-Emergent, Elective Medical Services, and Treatment Recommendations; 2020. Accessed August 31, 2021. https://www.cdc.gov/coronavirus/2019-ncov/healthcare-facilities/ index.html

2. Corley DA, Sedki M, Ritzwoller DP, et al. Cancer Screening during COVID19: A Perspective from NCI's PROSPR consortium. Gastroenterology. Published online October 21, 2020. https://doi.org/10.1053/j.gastro. 2020.10.030

3. Use of Colorectal Cancer Screening Tests (2018 Behavioral Risk Factor Surveillance System) | CDC. Published February 9, 2021. Accessed September 15, 2021. https://www.cdc.gov/cancer/colorectal/statistics/ use-screening-tests-BRFSS.htm

4. Issaka RB, Akinsoto NO, Strait E, Chaudhari V, Flum DR, Inadomi JM. Effectiveness of a mailed fecal immunochemical test outreach: a Medicare Advantage pilot study. Ther Adv Gastroenterol. 2020;13:1756284820945388. https://doi.org/10.1177/1756284820945388

5. Yu C, Skootsky S, Grossman M, et al. A Multi-Level Fit-Based Quality Improvement Initiative to Improve Colorectal Cancer Screening in a Managed Care Population. Clin Transl Gastroenterol. 2018;9(8):177. https://doi.org/10.1038/s41424-018-0046-Z

6. Jager M, Demb J, Asghar A, et al. Mailed Outreach Is Superior to Usual Care Alone for Colorectal Cancer Screening in the USA: A Systematic Review and Meta-analysis. Dig Dis Sci. 2019;64(9):2489-2496. https://doi. org/10.1007/s10620-019-05587-6

Publisher's Note Springer Nature remains neutral with regard to jurisdictional claims in published maps and institutional affiliations. 